\title{
In Vivo Evidence for a Lack of Central Effect of Ebastine, an Antihistaminic Agent, in Rats: a Microdialysis Study
}

\author{
Yuko Fujisaki, Yoshinori Itoh* and Ryozo Oishi \\ Department of Hospital Pharmacy, Faculty of Medicine, Kyushu University, 3-1-1 Maidashi, Higashi-ku, Fukuoka 812-8582, Japan
}

Received August 28, 2002 Accepted October 2, 2002

\begin{abstract}
The effects of ebastine and its active metabolite carebastine on brain dopamine uptake and the accessibility to brain were compared with those for a classical antihistaminic agent chlorpheniramine by using the microdialysis technique. Both carebastine and chlorpheniramine potently inhibited brain $\left[{ }^{3} \mathrm{H}\right]$ dopamine uptake and increased the extracellular concentration of dopamine in the striatum after local perfusion via microdialysis probes, although systemic injection of ebastine but not chlorpheniramine did not change the dopamine level. These findings suggest that neither ebastine nor carebastine affects central dopamine metabolism because of a limited access to brain, in spite of having a potent inhibitory action on neuronal dopamine uptake.
\end{abstract}

Keywords: Antihistaminic agent, Intracerebral dopamine microdialysis, Brain permeability

A variety of antihistaminic agents inhibit the neuronal uptake of monoamines $(1-3)$. We have previously reported that several antihistaminic agents augment the central action of L-dopa via inhibition of neuronal dopamine uptake in rodent brain (4). Among them, ebastine is a highly potent inhibitor of dopamine uptake in the rat striatum (4). Ebastine, a second generation non-sedative antihistaminic drug, is readily metabolized by the intestinal and hepatic oxidizing enzymes, such as cytochrome 3A4, into the active metabolite carebastine (5), and virtually no parent compound is detected in human plasma after its oral administration. Ebastine is practically devoid of central nervous system side effects (6), indicating that the compound poorly penetrates into brain. Since carebastine is a substrate of P-glycoprotein (7), the exclusion by this glycoprotein is considered to be associated with the limitation of its distribution into brain (7). However, there is still little in vivo neurochemical evidence for the poor penetration of ebastine or carebastine into brain. Therefore, in the present study, the effects of ebastine or carebastine on central dopamine metabolism were investigated in rats by using intracerebral microdialysis.

The present experiments were reviewed by the ethics committee for animal experiments at the Faculty of Medicine, Kyushu University and law No. 105 and notification No. 6 of the Japanese government. Male Wistar rats (8-

*Corresponding author. FAX: +81-92-642-5937

E-mail: yositou@st.hosp.kyushu-u.ac.jp week-old; Kyudo, Saga) were used. Ebastine was a gift from Dainippon Pharmaceutical Co. (Osaka). Carebastine was kindly donated from Kyowa Hakko Kogyo Co., Ltd. (Shizuoka). (+)-Chlorpheniramine maleate and nomifensine maleate were purchased from Sigma Chemical (St. Louis, MO, USA). [ $\left.{ }^{3} \mathrm{H}\right]$ Dopamine $(28.0 \mathrm{Ci} / \mathrm{mmol})$ was obtained from NEN Life Science Products (Boston, MA, USA). The uptake of $\left[{ }^{3} \mathrm{H}\right]$ dopamine was measured in the striatal membranes, as described by Richelson and Pfenning (8). Briefly, the crude synaptosomal membranes were prepared in ice-cold 2-[4-(2-hydroxyethyl)-1-piperazinyl]ethanesulfonic acid (HEPES) buffer containing $10 \mu \mathrm{M}$ pargyline and $1 \mathrm{mM}$ ascorbic acid. A $100-\mu 1$ aliquot of the synaptosomal suspension ( $2 \mathrm{mg}$ protein $/ \mathrm{ml}$ ) was added to $0.7 \mathrm{ml}$ of HEPES buffer and preincubated at $37^{\circ} \mathrm{C}$ for $5 \mathrm{~min}$. The uptake was determined by incubating the synaptosomal preparation with $10 \mathrm{nM}\left[{ }^{3} \mathrm{H}\right]$ dopamine for a further $5 \mathrm{~min}$ in the presence of various test compounds. The non-specific uptake was defined as that measured at $0^{\circ} \mathrm{C}$. The extracellular concentration of dopamine was measured by microdialysis in urethane-anesthetized rats. A microdialysis probe (I-shaped: A-I-8-02, Eicom, Kyoto) was inserted into the rat striatum and Ringer's solution was perfused at $2 \mu \mathrm{l} / \mathrm{min}$. After a $2-\mathrm{h}$ period of perfusion, microdialysates were collected every $20 \mathrm{~min}$ into tubes containing $10 \mu \mathrm{l}$ of $0.1 \mathrm{M}$ formic acid. For local drug perfusion, carebastine, chlorpheniramine or nomifensine was dissolved in Ringer's solution and perfused through the microdialysis probe. Throughout the experiment, rats were wrapped in a blanket 
A) Local perfusion of carebastine

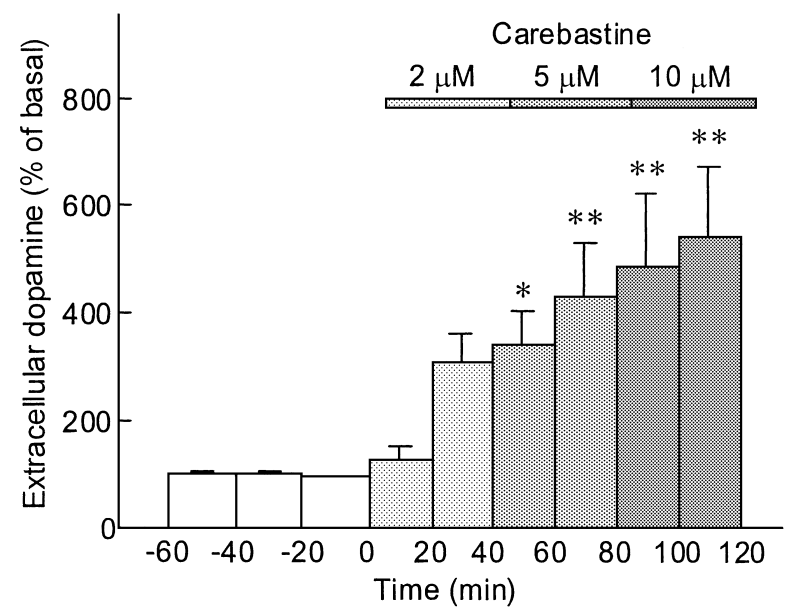

B) Local perfusion of carebastine after nomifensine

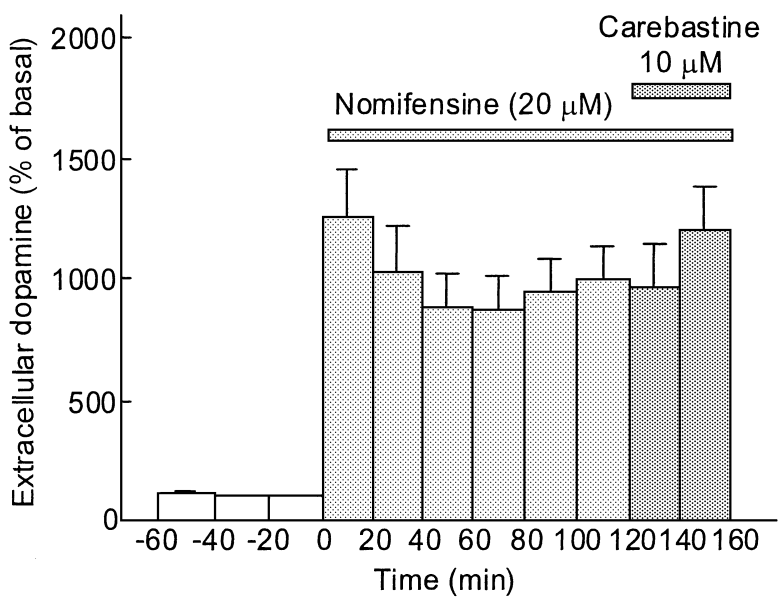

Fig. 1. Effect of local perfusion of carebastine in the absence (A) or presence of a dopamine uptake inhibitor nomifensine (B) on the extracellular concentration of dopamine in the striatum of urethane-anesthetized rats, as measured by intracerebral microdialysis. Each column represents the mean \pm S.E.M. of 5 animals. The basal dopamine concentration was $32.3 \pm 3.0 \mathrm{pg} / 20 \mathrm{~min}$ (A) or $38.9 \pm 8.9 \mathrm{pg} / 20 \mathrm{~min}$ (B) (mean \pm S.E.M.). $* P<0.05$, ${ }^{*} P<0.01$ vs average of 3 consecutive basal values (A); no significant difference was observed in dopamine levels before and after carebastine treatment (B).

to maintain constant body temperature. Dopamine was determined by HPLC with electrochemical detection, as described previously (9). Data were analyzed by one-way ANOVA, followed by Dunnett's test.

Ebastine, carebastine and chlorpheniramine inhibited the $\left[{ }^{3} \mathrm{H}\right]$ dopamine uptake into synaptosomal membranes of rat striatum with $\mathrm{Ki}$ values of $0.23 \mu \mathrm{M}, 0.16 \mu \mathrm{M}$ and $0.92 \mu \mathrm{M}$, respectively (data not shown).

Since the peripherally administered ebastine is mostly metabolized to carebastine (5), the effect of local perfusion of carebastine on striatal dopamine concentration was examined. As shown in Fig. 1A, local perfusion of carebastine $(2-10 \mu \mathrm{M})$ produced a concentration-dependent increase in dopamine concentration. However, the effect of carebastine was no longer observed when it was applied after blockade of dopamine uptake with $20 \mu \mathrm{M}$ nomifensine (Fig. 1B). Therefore, it is suggested that the increase in dopamine level induced by local carebastine perfusion results predominantly from dopamine uptake inhibition. Likewise, the local perfusion of chlorpheniramine (10$50 \mu \mathrm{M})$ elevated concentration-dependently the extracellular dopamine concentration (Fig. 2). In spite of a potent dopamine uptake inhibitory action of carebastine, intraperitoneal injection of the parent compound ebastine $(20 \mathrm{mg} / \mathrm{kg}$ ) had no influence on the level of extracellular dopamine (Fig. 3A). On the other hand, systemic injection of chlorpheniramine ( $20 \mathrm{mg} / \mathrm{kg}$, i.p.) significantly increased the extracellular concentration of dopamine (Fig. 3B).

In the present study, carebastine was found to be a potent

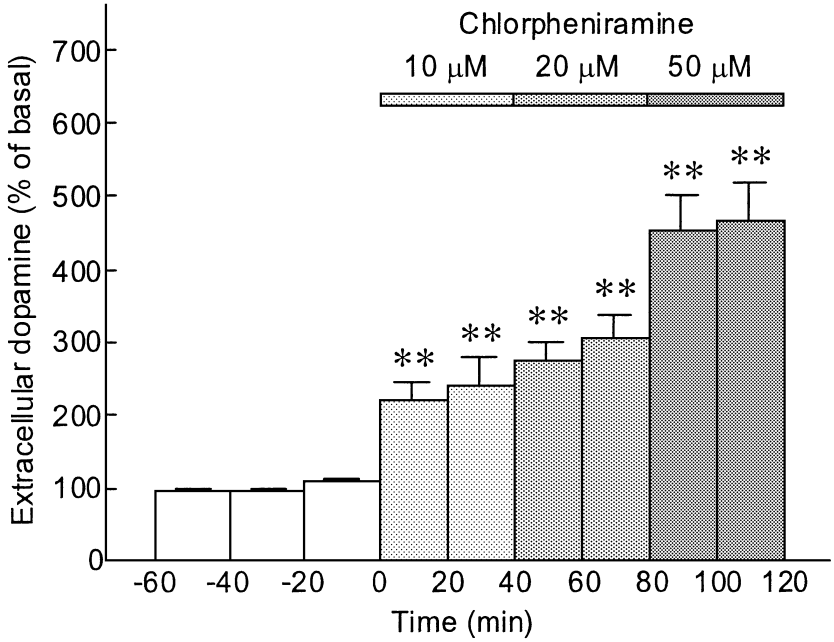

Fig. 2. Effect of local perfusion of chlorpheniramine on the extracellular concentration of dopamine in the striatum of urethaneanesthetized rats. Each column represents the mean \pm S.E.M. of 5 animals. The basal dopamine concentration was $24.9 \pm 4.7 \mathrm{pg}$ $/ 20$ min. $* * P<0.01$ vs average of 3 basal values.

inhibitor of neuronal dopamine uptake, as evidenced by uptake inhibition using $\left[{ }^{3} \mathrm{H}\right]$ dopamine as well as the microdialysis study. A similar but less potent dopamine uptake inhibition was observed with chlorpheniramine.

It has been reported that oral doses of ebastine are well absorbed and almost exclusively metabolized to the biologically active acidic metabolite carebastine both in 
A) Systemic ebastine injection

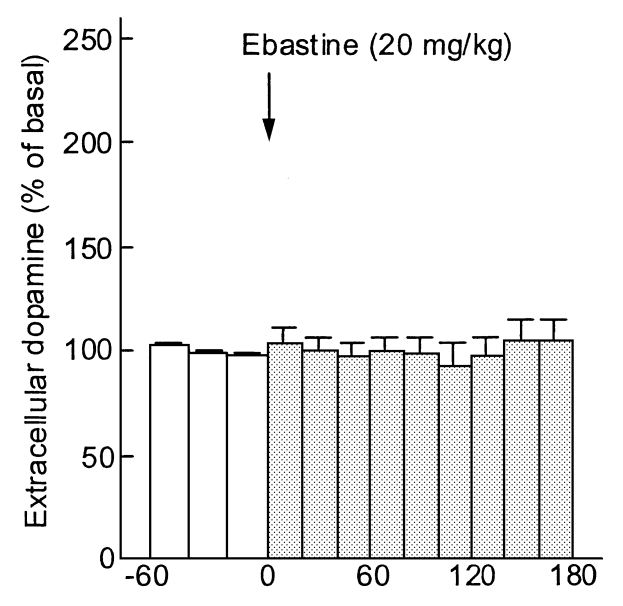

B) Systemic chlorpheniramine injection

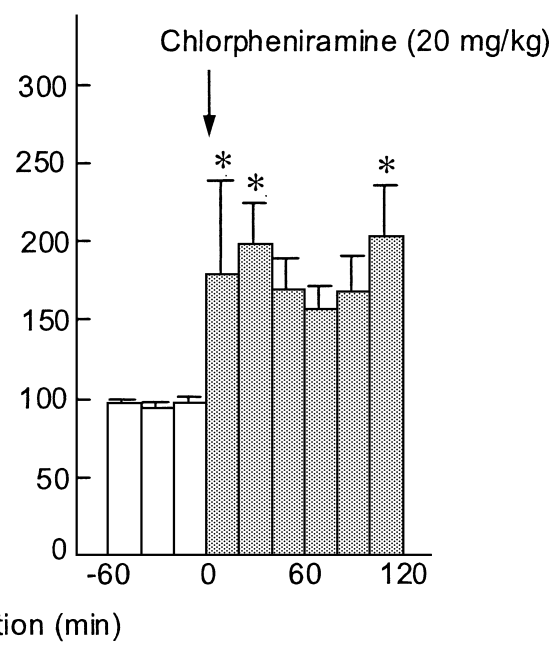

Fig. 3. Comparative effects of systemic administration of ebastine (A) and chlorpheniramine (B) on the extracellular concentration of dopamine in the striatum of urethane-anesthetized rats. Ebastine or chlorpheniramine was injected i.p., as shown by arrows. Each column represents the mean \pm S.E.M. of 4 (A) or 5 (B) experiments. The basal dopamine concentration was $26.9 \pm 9.3 \mathrm{pg} / 20 \mathrm{~min}(\mathrm{~A}: \mathrm{N}=4)$ or $20.9 \pm 4.0 \mathrm{pg} / 20 \mathrm{~min}(\mathrm{~B}: \mathrm{N}=5) .{ }^{*} P<0.05$ vs average of 3 basal values.

humans and animals (10). Therefore, in the present study, we determined whether the extracellular dopamine concentration increases after systemic injection of ebastine. Ebastine even at $20 \mathrm{mg} / \mathrm{kg}$ (i.p.) did not enhance the extracellular dopamine level in the rat striatum. On the other hand, systemic injection of chlorpheniramine $(20 \mathrm{mg} / \mathrm{kg}$, i.p.) significantly increased the dopamine concentration. It has been shown that chlorpheniramine inhibits neuronal dopamine uptake and decreases in the levels of dopamine metabolites 3,4-dihydroxyphenylacetic acid and homovanillic acid in rodent brains $(2-4)$. Thus, our present data also indicated that the compound easily penetrates into brain to elevate extracellular dopamine concentration by inhibiting dopamine uptake. The classical antihistaminic agents are associated with adverse central nervous system effects such as sedation, since they easily penetrate into brain to reach concentrations that sufficiently block central $\mathrm{H}_{1}$ receptors (11). In contrast, second generation antihistaminic compounds including ebastine are generally non-sedative because of the poor penetration into brain $(12,13)$. Thus, the present in vivo data clearly indicate that the brain permeability of ebastine or carebastine is extremely limited. The distribution of carebastine into brain may be severely regulated by P-glycoprotein (7).

In conclusion, both ebastine and carebastine revealed potent inhibitory action on neuronal dopamine uptake. Thus, carebastine, when perfused locally into rat striatum, markedly elevated the extracellular concentration of dopamine. However, systemic administration of ebastine did not increase the dopamine level. Therefore, the present in vivo findings suggest that the brain permeability of ebastine or its predominant metabolite carebastine is too severely limited to fulfill its potent inhibitory action on neuronal dopamine uptake.

\section{REFERENCES}

1 Tuomisto J and Tuomisto L: Effects of histamine and histamine antagonists on the uptake and release of catecholamines and 5-HT in brain synaptosomes. Med Biol 58, 33 - 37 (1980)

2 Shishido S, Oishi R and Saeki K: In vivo effects of some histamine $\mathrm{H}_{1}$-receptor antagonists on monoamine metabolism in the mouse brain. Naunyn Schmiedebergs Arch Pharmacol 343, $185-189$ (1991)

3 Oishi R, Shishido S, Yamori M and Saeki K: Comparison of the effects of eleven histamine $\mathrm{H}_{1}$-receptor antagonists on monoamine turnover in the mouse brain. Naunyn Schmiedebergs Arch Pharmacol 349, 140 - 144 (1994)

4 Matsunaga K, Sato T, Shuto H, Tsuruta Y, Suemaru K, Gomita $\mathrm{Y}$ and Oishi R: Inhibition of neuronal dopamine uptake by some antiallergic drugs. Eur J Pharmacol 350, 165 - 169 (1998)

5 Hashizume T, Mise M, Terauchi Y, O L, Fujii T, Miyazaki H and Inaba $\mathrm{T}$ : $N$-Dealkylation and hydroxylation of ebastine by human liver cytochrome P450. Drug Metab Dispos 26, $566-$ 571 (1998)

6 Roberts DJ: A preclinical overview of ebastine. Studies on the pharmacological properties of a novel histamine $\mathrm{H}_{1}$ receptor antagonist. Drugs 52, Suppl 1, 8 - 14 (1996)

7 Tamai I, Kido Y, Yamashita J, Sai Y and Tsuji A: Blood-brain barrier transport of $\mathrm{H}_{1}$-antagonist ebastine and its metabolite carebastine. J Drug Target 8, 383 - 393 (2000)

8 Richelson E and Pfenning M: Blockade by antidepressants and related compounds of biogenic amine uptake into rat brain 
synaptosomes: Most antidepressants selectively block norepinephrine uptake. Eur J Pharmacol 104, 277 - 286 (1984)

9 Itoh Y, Oka M, Ukai Y and Kimura K: A novel $\mathrm{Na}^{+} / \mathrm{Ca}^{2+}$ channel blocker NS-7 inhibits evoked but not spontaneous dopamine release from rat striatum, as measured by intracerebral microdialysis. Neurosci Lett 252, 203 - 206 (1998)

10 Fujii T, Matsumoto S, Amejima H, Hatoyama T, Nakao M, Kagemoto A, Tanaka K and Miyazaki H: Absorption, distribution, metabolism and excretion of $\left[{ }^{14} \mathrm{C}\right]$ ebastine after a single administration in rats. Arzneimittelforschung 44, 527-538 (1994)

11 Nicholson AN, Pascoe PA, Turner C, Ganellin CR, Greengrass
PM, Casy AF and Mercer AD: Sedation and histamine $\mathrm{H}_{1^{-}}$ receptor antagonism: studies in man with the enantiomers of chlorpheniramine and dimethindene. Br J Pharmacol 104, 270 276 (1991)

12 Chishty M, Reichel A, Siva J, Abbott NJ and Begley DJ: Affinity for the $P$-glycoprotein efflux pump at the blood-brain barrier may explain the lack of CNS side-effects of modern antihistamines. J Drug Target 9, 223 - 228 (2001)

13 Takizawa T, Matsumoto J, Tohma T, Kanke T, Wada Y, Nagao $\mathrm{M}$, Inagaki $\mathrm{N}$, Nagai $\mathrm{H}$, Zhang $\mathrm{MQ}$ and Timmerman HR: VUF-K-8788, a periphery-selective histamine $\mathrm{H}_{1}$ antagonist with anti-pruritic activities. Jpn J Pharmacol 86, 55 - 64 (2001) 